\title{
Evolución de los tiempos compuestos en portugués durante los siglos XVI y XVII
}

Recibido: 22/04/2014

Aceptado: 23/06/2014

\section{RESUMEN:}

En este trabajo se estudia la evolución de los tiempos compuestos en portugués durante un período que no había sido estudiado aún: desde mediados del siglo XVI hasta mediados del siglo XVII. De esta forma es posible tener una visión completa del uso de los tiempos compuestos en el momento de la constitución del portugués clásico o moderno. Para ello se ha escogido la obra de tres autores: Sebastião Toscano, Duarte Nunes de Leão y Francisco Rodrigues Lobo.

PALABRAS CLAVE: tiempos compuestos; lengua portuguesa; influencia del español; diacronía

\section{ABSTRACT:}

In this paper we study the evolution of the compound tenses in Portuguese during a period of time that had never been studied: from mid $16^{\text {th }}$ century to mid $17^{\text {th }}$ century. Therefore it is possible to have a complete vision of the use of the compound tenses in the moment of classical or modern Portuguese formation. For this study we have chosen the work of three authors: Sebastião Toscano, Duarte Nunes de Leão and Francisco Rodrigues Lobo.

KEYWORDS: compound tenses; Portuguese language; Spanish influence; diachrony 
Uno de los indicadores elegidos para estudiar la transición del portugués antiguo al moderno (y, en consecuencia, para la creación de una lengua clásica a lo largo del siglo XVI) es la constitución de los tiempos compuestos, de lo que se ha ocupado especialmente la investigadora brasileña Rosa Virgínia Mattos e Silva ${ }^{1}$. El primero de los fenómenos que interesa a este respecto es el de la progresiva sustitución del verbo haver por el verbo ter como auxiliar. En el análisis que Paulo Osório lleva a cabo sobre el Corpus Informatizado do Português Medieval de la Universidade Nova de Lisboa ${ }^{2}$, entre los siglos XIII y XVI observa una lenta progresión de los casos de ter $+P P$, desde una presencia inferior al $10 \%$ en el siglo XIII hasta aparecer en dos tercios de los casos ya en el siglo $\mathrm{XVI}^{3}$ :

\begin{tabular}{|c|c|c|c|c|}
\cline { 2 - 5 } \multicolumn{1}{c|}{} & siglo XIII & siglo XIV & siglo XV & siglo XVI \\
\hline haver $+P P$ & $92,90 \%$ & $88,20 \%$ & $45,50 \%$ & $31,10 \%$ \\
\hline ter $+P P$ & $7,10 \%$ & $11,80 \%$ & $55,50 \%$ & $68,90 \%$ \\
\hline
\end{tabular}

Tabla 1. Evolución de ter y haver en los tiempos compuestos

1 Entre otros trabajos, v. «Para uma caracterização do período arcaico do português», D.E.L.T.A., 10 (especial), 1994, pp. 247-276. Posteriormente, interesa sobre todo el análisis realizado sobre la obra de João de Barros ( «Vitórias de ter sobre haver nos meados do século XVI: usos e teoria em João de Barros», O português quinhentista: estudos linguísticos, Rosa Virgínia Mattos e Silva y Américo Venâncio Lopes Machado Filho, organizadores, Salvador, Universidade Federal da Bahia / Universidade Estadual de Feira de Santana, 2002, págs. 119-142) y las cartas de D. João III («A variação ser/estar e haver/ter nas Cartas de D. João III entre 1540 e 1553: comparação com os usos coetâneos de João de Barros», O português..., págs. 143-160).

2 V. http://cipm.fcsh.unl.pt/ (consultado por última vez el 3/12/2013).

3 Osório, Paulo: «Linguística histórica e história da língua. Aportações teóricas e metodológicas», I Simpósio Mundial de Estudos da Língua Portuguesa, São Paulo, 1 a 5 de setembro de 2008, pág. 8. Disponible en http://www.fflch.usp.br/dlcv/lport/pdf/ slp04/01.pdf (consultado por última vez el 2/12/2013). 
Aunque Paulo Osório solo contabiliza en su estudio los casos en que no hay concordancia entre el verbo y el complemento directo, con el propósito de atenerse exclusivamente a los tiempos compuestos ya perfectamente gramaticalizados, los resultados siguen siendo igualmente significativos, pues la concordancia con el complemento directo afecta en este período por igual a ter y haver.

Cuando el análisis se dirige a períodos mucho más restringidos de la época clásica y a la obra de determinados autores, los resultados empiezan a revelar matices y detalles que dilucidan mucho mejor sobre la forma como se fue estableciendo el modelo de ter $+P P$ en sustitución de haver $+P P$. La obra de Bernardim Ribeiro nos avisa de algunas peculiaridades que puede contener la lengua literaria, pues determinados registros estilísticos (arcaizantes, propios de caballerías y antiguas leyendas, etc.) permiten el uso de formas que ya en su momento podían ser percibidas como obsoletas, si bien en general se constata, gracias al análisis de la obra bernardiniana, que en el primer tercio del siglo XVI existía un uso muy restringido, casi insignificante, de haver como verbo auxiliar en la formación de los tiempos compuestos ${ }^{4}$.

Pocos años después, en las décadas de los 40 y 50, como señala Rosa Virgínia Mattos e Silva, haver + PP no aparece en la obra de João de Barros: ni existe en la lengua de este autor, ni él mismo refiere su uso cuando describe los "tempos per rodeo" (tiempos compuestos) en su Gramática da língua portuguesa $(1540)^{5}$. Y

4 V. Carrasco González, Juan M.: «Uso de haver en la Menina e Moça: Bernardim Ribeiro en la frontera del portugués arcaico», La lengua, lugar de encuentro. Actas del XVI Congreso Internacional de la Asociación de Lingüistica y Filología de la América Latina (Alcalá de Henares, 6-12 de junio de 2011), Ana María Cestero Mancera, Isabel Molina Martos y Florentino Paredes García, editores, Alcalá de Henares, Universidad de Alcalá de Henares, 2012, págs. 2515-2524 (disponible en http://alfal2011.mundoalfal. org/index.html\#/pdf/284alfal.pdf, última consulta el 4/12/2013); y Carrasco González, Juan M.: «Algunos indicadores del portugués clásico en la obra de Bernardim Ribeiro», Estudis Romànics, vol. 35, 2013, págs. 173-188. 
el mismo resultado obtiene la lingüista brasileña cuando estudia la lengua no literaria, pero sí culta, propia de la administración cortesana: no hay ningún caso de haver como auxiliar de los tiempos compuestos en las cartas de D. João III, fechadas entre 1541 y 1551, según la edición de Ford de $1931^{6}$.

Después de observar la progresiva sustitución de haver $+P P$ por ter $+P P$, hasta el punto de que durante la primera mitad del siglo XVI haver + PP prácticamente ha dejado de usarse, al menos en la lengua culta y literaria, resulta sorprendente la situación que nos encontramos un siglo más tarde, a mediados del XVII: en la obra de Francisco Manuel de Melo, la mayoría escrita en la década de 1650, el uso de haver como auxiliar en los tiempos compuestos no solo se había recuperado, sino que era mayoritario $(63.3 \%$ de haver frente a $36.7 \%$ de tiempos compuestos con ter). ${ }^{7}$ La varianza extrema del uso de haver + PP en las distintas obras del autor y su uso al modo del castellano y no del portugués (por ejemplo, sin concordar con el complemento directo, como todavía podía hacer el verbo ter en estas construcciones) me llevan a creer que, más que una pervivencia de haver $+P P$, hay una recuperación de esta construcción por influencia del español en un período en que esta lengua, al menos en la administración y en ambientes cultos de Portugal, tenía una presencia extraordinaria y gozaba de gran prestigio literario. Se puede deducir de ello que ya la construcción de haver $+P P$ había desaparecido de la lengua hablada en la etapa final del portugués medio (o antiguo) y principios de la lengua clásica (o moderna), y no a finales del siglo XX, cuando finalmente, dentro del paradigma de la conjugación, una gramática

6 Mattos e Silva, R.V.: «A variação...» La edición de J. D. M. Ford utilizada en este estudio es Letters of John III King of Portugal: 1521-1557, Cambridge, Harvard University Press, 1931.

7 V. Carrasco González, Juan M.: «Influencia del español en la prosa barroca portuguesa: los tiempos compuestos», RILCE, 31.1, 2015, págs. $79-96$ (en publicación) 
portuguesa opta por eliminar el verbo haver como auxiliar en la formación de los tiempos compuestos porque, como señalan sus autoras a pie de página, "deixou de se utilizar na linguagem coloquial"s.

El primero de los objetivos de este trabajo consistirá en estudiar cómo se produjo la recuperación de haver $+P P$ desde mediados del siglo XVI hasta mediados del siglo XVII mediante el análisis de la obra de tres autores que cubren ese período: Sebastião Toscano, Duarte Nunes de Leão y Francisco Rodrigues Lobo.

He escogido un corpus de lengua culta, literaria y no literaria, porque permite una comparación con la evolución de los tiempos compuestos según estudios previos, realizados todos ellos en corpora de estas características. Naturalmente, será muy interesante comprobar también en otros trabajos cuál es la evolución de estas construcciones en otros registros de lengua, pero no es ese el objeto del presente estudio. Por otro lado, dado que se ha observado ya una posible influencia del español en la recuperación de haver $+P P$, son precisamente los autores cultos de obra literaria, religiosa, humanística, administrativa, etc., los más expuestos a la influencia de carácter vertical de la lengua española, por lo que será aquí donde habrá que empezar a estudiar los efectos de esa influencia en el período clásico.

El trabajo se completará con el estudio, en el corpus propuesto, de otras características propias de la evolución de los tiempos compuestos que aún no han sido objeto de atención suficiente por parte de los especialistas en el ámbito de la lengua portugue-

8 Mateus, Maria Helena Mira; Brito, Ana Maria; Duarte, Inês Silva; y Faria, Isabel Hub: Gramática da Língua Portuguesa, Coimbra, Livraria Almedina, 1983, pág. 284. En el portugués de Brasil tampoco se usa (en nuestra opinión, desde el siglo $\mathrm{XVI}$ ) si no es en la lengua escrita culta: "Já no português brasileiro (PB) contemporâneo o verbo haver perdeu todos os domínios de posse e perdeu também sua posição de auxiliar, restringindo-se a construções raras" (Floripi, Simone: «O comportamento do verbo haver no texto de Pero de Gândavo", Revista Elecrônica Via Litterae, v. 1, n.1, jul./dez. 2009, pág. 177, disponible en www.unucseh.ueg.br/vialitterae, consultado el 12/01/2014). 
sa, como es la pervivencia de ser como auxiliar en los tiempos compuestos, el uso de un pretérito anterior inexistente en la actualidad y el grado de gramaticalización de los verbos auxiliares según dos aspectos diferentes: la interpolación de elementos entre el auxiliar y el participio y la anteposición del participio al auxiliar.

\section{El corpus objeto de análisis}

Se han seleccionado tres obras en prosa de carácter muy distinto que responden a tres registros diferentes de lengua culta: religioso, científico (humanístico) y literario. Con ellas se abarca el período de la segunda mitad del siglo XVI y la primera del XVII:

- Sebastião Toscano, Mística Teologia, Lisboa, 1568. Utilizo un ejemplar de esta primera edición en portugués que perteneció al convento de Santa Rita de Coimbra y que actualmente pertenece a una biblioteca particular9. Para suplir los defectos del ejemplar (pues le faltan las hojas 49, 57, 58, 63, 64, 80, 81, 97, 104, 105, 113 y 120), he utilizado el ejemplar digitalizado en el portal de la Biblioteca Nacional de Portugal ${ }^{10}$.

- Duarte Nunes de Leão, Ortografia Portuguesa, Lisboa, 1576. Utilizo el ejemplar de esta primera edición digitalizado en el portal de la Biblioteca Nacional de Portugal ${ }^{11}$.

9 MYSTICA theologia, na qual se mostra o verdadeiro caminho pera subir ao çeo, cõforme a todos os estados da vida humana cõposta por o padre M. F. Sebastião Toscano: da ordẽ dos ermitães de sancto Agostinho [...] acabouse o presente liuro nesta mui nobre e sempre leal cidade de Lixboa ẽ casa de Francisco Correa impressor, aos xxvj. dias do mes Dabril, de 1568

10 V. http://purl.pt/16321 (última consulta realizada el 30/12/2013). La digitalización contiene algunos errores: las páginas $71 \mathrm{v}$ y 72r no fueron digitalizadas y la página 136r fue digitalizada dos veces. El ejemplar pertenece a la Biblioteca Nacional de Portugal, signatura res-4725-p.

11 V. http://purl.pt/15 (última consulta realizada el 30/12/2013). Corresponde al ejemplar perteneciente a la misma Biblioteca Nacional con la signatura res-277-2-v: Orthographia da lingoa portuguesa [...] pelo licenciado Duarte Nunez do Lião. Em Lisboa: per Ioão de Barreira, 1576. 
- Francisco Rodrigues Lobo, Corte na Aldeia e Noites de Inverno, Lisboa, 1619. Utilizo un ejemplar de la segunda edición portuguesa (Lisboa, 1649) que también está accesible en el portal de la Biblioteca Nacional de Portugal ${ }^{12}$.

Sebastião Toscano, nacido en Lisboa en 1515 y muerto en Oporto en 1583, escribió obras en latín, portugués y castellano. Su Mística Teologia lo convierte en la más alta expresión de la mística portuguesa del Renacimiento. Esta obra, que podemos considerar representativa de la lengua culta de la segunda mitad del siglo XVI, tuvo una rápida divulgación y conoció una versión latina el mismo año de su publicación en portugués, así como una edición española poco tiempo después (en 1573).

El jurista, historiador y gramático Duarte Nunes de Leão nació en la ciudad de Évora hacia 1530 y murió en Lisboa en 1608. No solo escribió en portugués, pues también tiene algunas obras de carácter historiográfico en castellano. Se puede considerar un autor representativo de finales del siglo XVI y primeros años del XVII, ya en plena época de unión de las coronas de España y Portugal, momento álgido de la presencia de la lengua y la cultura españolas en el reino vecino. Su Ortografia Portuguesa es una de las obras más afamadas entre los humanistas que se dedicaron al estudio de la lengua portuguesa.

Corte na Aldeia e Noites de Inverno es la única obra estrictamente literaria. Su autor nació en Leiria en 1580 y murió en un naufragio sufrido en el río Tajo en 1622. Utilizó tanto el español como el portugués para escribir una obra muy vinculada al bucolismo y a la difusión del barroco en Portugal. Fue muy conocido y citado por los autores españoles de la época. Su Corte na Aldeia

12 V. http://purl.pt/17316 (última consulta realizada el 30/12/2013). Corresponde al ejemplar perteneciente a la misma Biblioteca Nacional con la signatura res6593-p: Corte na aldea e noites de inverno de Francisco Rõz Lobo. Em Lisboa: por Antonio Aluarez Impr. DelRey, 1649. 
conoció una traducción castellana en 1622, al poco de editarse en Portugal, y se puede considerar característica de la primera mitad del siglo XVII.

Para el análisis del corpus he utilizado el programa de herramientas lingüísticas AntConc 3.2.3w (Windows) desarrollado por Laurence Anthony en la Universidad de Waseda (Japón). ${ }^{13}$

\section{Ter y haver en la formación de los tiempos compuestos}

El uso de haver $+P P$ ofrece unos resultados muy dispares y significativos en los tres autores analizados. Sabiendo que a mediados del siglo XVI había dejado de usarse, sorprende que el autor con una frecuencia mayor de ocurrencias sea el más antiguo, Sebastião Toscano: el 77.1\% de casos en la Mística Teologia, 27 en total, corresponden a tiempos compuestos con el verbo haver. Veamos algunos ejemplos:

E nosso señor Iesu Christo auendo dado no monte a sua ley sancta, recapitulou

Auia este mancebo perguntado ao Senhor, q faria

AVendo ho senhor mostrado o caminho do çeo

os filhos de Israel auião quebrantado ho pacto

emendar seus defeytos em comparação das cousas q ouner contemplado

En cuanto a los otros dos autores, presentan una situación similar de signo contrario: ninguna ocurrencia en Duarte Nunes de Leão y una frecuencia mínima (5.3) en Francisco Rodrigues Lobo. Estos son los casos de haver + PP en Corte na aldeia:

fingio hum dia saindo cõ alegre semblante auerlhe fallado

13 V. http://www.antlab.sci.waseda.ac.jp/index.html. 
entaõ me naõ descubria o pejo com que ficou de me auer visto homem q quizesse viuer mais despois de auer testado com o pesar de vos auer offendido elle era o que the auia escolhido tal esposa

En la Tabla 2 vemos las ocurrencias y frecuencias de uso de ter y haver en la formación de los tiempos compuestos. Ahí se puede apreciar bien la notable varianza en el uso de haver $+P P$, desde 77.1 hasta el 0 o 5.3 .

\begin{tabular}{r|c|c|} 
& TER + PP & HAVER + PP \\
\cline { 2 - 3 } $\begin{array}{r}\text { Mística Teologia } \\
\text { (frecuencia) }\end{array}$ & $\begin{array}{l}8 \text { oc. } \\
(32.9)\end{array}$ & $\begin{array}{l}27 \text { oc. } \\
(77.1)\end{array}$ \\
\cline { 2 - 3 } Ortografia Portuguesa & 20 oc. & 0 oc. \\
(frecuencia) & $(100)$ & $(0)$ \\
\cline { 2 - 3 } Corte na Aldeia e Noites de Inverno & 90 oc. & 5 oc. \\
(frecuencia) & $(94.7)$ & $(5.3)$ \\
\cline { 2 - 3 } & &
\end{tabular}

Tabla 2. TER y HAVER en tiempos compuestos

Es cierto que tanto en Ortografia Portuguesa como en Corte na Aldeia hay algunos casos de ter $+P P$ que no podemos considerar propiamente tiempos compuestos, sino como verbo [+transitivo] seguido de complemento directo (con el participio haciendo funciones de adjetivo). Esto es así no tanto porque el participio haga la función de adjetivo (pues ocurre frecuentemente en la construcción ter $+P P$, incluso siendo tiempo compuesto, como veremos a continuación), sino porque en estos casos concretos la construcción ter + $P P$ no expresa la noción de tiempo pasado. Se trata de 3 ocurrencias en Ortografia Portuguesa y 2 ocurrencias en Corte na Aldeia:

os nomes femininos, que em Portugues se acabão em. ãa . teem a mesma differença de seus masculinos acabados em. ão . que teem os Latinos acabados em . ana . dos acabados em anus (Ortografia) 
No que muitos teem errada opinião, cuidando, que são diphthongos (Ortografia)

cuidando, q os tomamos dos Gregos, que no masculino, \& feminino do primeiro caso os teem [artículos] aspirados, dizendo, $\delta, \eta$ (Ortografia)

o menor lugar em que se empregaua a vista tinha desusados estremos de fermosura (Corte) (Corte)

Pindaro, que tem estilada quinta essencia dos louuores escholasticos

A pesar de la existencia de estos casos, su contabilización o no apenas altera la frecuencia final de ter $+P P$ en ambas obras, que será siempre de 100 en Ortografia Portuguesa y cerca de 95 en Corte na Aldeia e Noites de Inverno. Hay que preguntarse, por lo tanto, a qué se debe la varianza extrema que se muestra en la Tabla 2. Por lo que se refiere a Duarte Nunes de Leão y a Francisco Rodrigues Lobo, no hay anomalía ninguna. Nunes de Leão, autor de finales del siglo XVI, mantiene la situación que se produce a mediados de siglo: haver $+P P$ ha dejado de usarse a favor de ter $+P P$. Rodrigues Lobo, autor algo posterior, no difiere sustancialmente de él, pues utiliza casi exclusivamente ter $+P P$. Sin embargo, los raros ejemplos de haver $+P P$ en este autor son significativos, pues nos advierten de que la recuperación del auxiliar haver para la construcción de los tiempos compuestos se había iniciado ya.

El uso de haver + PP en Sebastião Toscano, en una frecuencia inversa a la de los otros dos autores y en contradicción con el uso que se debería esperar cuando escribe la obra, no parece que se deba a un posible uso arcaizante regional o dialectal, pues el teólogo agustino nació en Lisboa. Pudiera pensarse que, habiendo nacido en 1515, se limita a reproducir en la obra un uso que él conoció en su infancia o primeros años de juventud, aunque resulta difícil de creer si pensamos que haver $+P P$ ya había desaparecido en autores de una generación anterior a él (Bernardim Ribeiro o João de Barros). Aun admitiendo la posibilidad de que Sebastião Toscano hubiera conocido un uso "vivo" de haver + PP en la len- 
gua hablada de su infancia, no es admisible pensar que se diese a la labor de redactar una obra culta, no marcada lingüísticamente, "resucitando" la forma de hablar de sus abuelos.

En mi opinión, encontramos en Sebastião Toscano una situación semejante a la que presenta D. Francisco Manuel de Melo: recupera un uso tradicional del verbo haver en portugués (del que aún había memoria y que podía leerse en autores previos) gracias al castellano, que era adoptado cada vez más como modelo de lengua culta y literaria. La extraordinaria varianza advertida entre Toscano, por un lado, y Nunes de Leão y Rodrigues Lobo, por otro, es semejante a la que encontramos entre las distintas obras de Melo, y solo puede ser explicado como un uso ya exclusivamente relegado a la lengua culta y escrita de haver + $P P$, pues, si la presencia de haver como auxiliar de tiempos compuestos fuese propia del portugués hablado en la segunda mitad del siglo XVI y principios del XVII, su frecuencia sería similar en todos los autores y en todas las obras. No obstante, es importante advertir que todavía a finales del siglo XVI y en las primeras décadas del XVII esta recuperación de haver + PP no se había extendido suficientemente en la lengua culta y literaria, pues está ausente de autores como Nunes de Leão o es casi inapreciable en Rodrigues Lobo.

Un indicio de que haver $+P P$ se había recuperado en Francisco Manuel de Melo tomando como modelo el español se encuentra en el hecho de que el participio no concuerda en género y número con el CD. Antes de los primeros años del siglo XVI, cuando haver y ter eran usados indistintamente para la construcción de los tiempos compuestos, el participio podía concordar con el CD en los mismos casos y con la misma frecuencia cuando el auxiliar era ter o haver. De ahí se deduce que, si hubiese sido una mera recuperación de la construcción tradicional portuguesa, los participios con haver deberían concordar de forma similar a como aún lo hacían con ter en la segunda mitad del siglo XVI y en el siglo XVII. 
Para el análisis de la concordancia del participio, debemos descartar en primer lugar, pues no es posible dilucidar tal concordancia, los casos en que el CD es masculino singular (ejemplo de Mística Teologia: AVendo o senhor mostrado o caminho do çeo), o es neutro pronominal o cuyo antecedente es una oración (ejemplo de Ortografia Portuguesa: como teemos dicto do .a.), o cuando el verbo es [-transitivo] o posee CD Ø (ejemplo de Corte na Aldeia e Noites de Inverno: que nesta idade tem chegado à mayor perfeição). También hemos descartado los casos en que ter $+P P$ no expresa noción temporal, si bien en estos casos, obviamente, la concordancia es obligada.

\begin{tabular}{rlc|c|c|} 
& \multicolumn{1}{r}{ Mística Teologia } & Ortografia Portuguesa & Corte na Aldeia \\
\cline { 2 - 4 } Total de ocurrencias: & 4 & 3 & 37 \\
\cline { 2 - 4 } con concordancia (frecuencia): & $4(100)$ & $2(66.7)$ & $21(56.8)$ \\
\cline { 2 - 4 } sin concordancia (frecuencia): & $0(0)$ & $1(33.3)$ & $16(43.2)$ \\
\cline { 2 - 4 }
\end{tabular}

Tabla 3. Concordancia con el verbo TER

En el caso de la construcción ter $+P P$, como se puede observar en la Tabla 3, todas las obras coinciden en mantener ocurrencias de concordancia en una frecuencia mayoritaria, hasta el punto de que en Mística Teologia todos los casos son de concordancia. Algunos ejemplos de concordancia:

\section{Teologia)}

a outra parte onde tinha a cabeça iuclinada [sic = inclinada] (Mística

regras, que teemos dadas, no capitulo desta letra .s. (Ortografia Portuguesa)

tem conquistada toda a terra de Hespanha (Corte na Aldeia)

Ejemplos de no concordancia con el verbo ter en Nunes de Leão y Rodrigues Lobo:

não screueria assi os outros [nomes] que o vso, por não serem nomes mui cõmũs, não tiuesse mudado (Ortografia Portuguesa) 


\title{
vingança lhe tem dado a ventura (Corte na Aldeia)
}

Por el contrario, en el caso de haver $+P P$ no hay ni un solo caso de concordancia. Cierto es que en Corte na Aldeia no hay ningún caso que cumpla las condiciones para evaluar la concordancia tal y como las establecimos anteriormente ${ }^{14}$, pero Mística Teologia, que posee 27 casos de haver $+P P$ y, de ellos, 8 que cumplen con las condiciones, no presenta ninguna ocurrencia de concordancia. Veamos algunos ejemplos de no concordancia en la obra de Sebastião Toscano:

\author{
por auer cõprado, cinco jugadas de bois \\ e os outros por auer cõprado terras \\ em comparação das cousas q ouuer contemplado
}

La ausencia de concordancia en haver $+P P$, al contrario de lo que sucede en ter $+P P$ y del uso tradicional de haver $+P P$ en portugués, es un indicio sólido para sospechar que Toscano (como más tarde Francisco Manuel de Melo) recupera este uso tomando como modelo a la lengua castellana y, naturalmente, sería un uso relegado ya exclusivamente a la lengua culta escrita. La recuperación es aún muy parcial en la segunda mitad del siglo XVI y primera del XVII, pues, al lado de autores que sienten especial predilección por haver $+P P$ (como Sebastião Toscano), hay otros que no lo usan en absoluto (Duarte Nunes de Leão) o lo usan en una frecuencia ínfima (Francisco Rodrigues Lobo). Esta extraordinaria varianza en la frecuencia de uso según distintos autores $\mathrm{u}$ obras es también, como se dijo anteriormente, un indicio de ser una construcción ajena a la lengua común y hablada en

14 Hay un ejemplo que aparentemente posee $\mathrm{CD}$ femenino: elle era o que the auia escolhido tal esposa [a Florisa]. Sin embargo, se trata de una errata de impresión, pues en lugar de esposa debería decir esposo. 
todo este período, de modo que parece necesaria la intervención de una causa exterior (la influencia del español) para explicar la recuperación de su uso en portugués.

\section{Otros aspectos de la formación de los tiempos compuestos en portugués}

La concordancia del CD con el auxiliar ter es un rasgo arcaizante que muestra la incompleta gramaticalización de los tiempos compuestos en portugués en este período y que aún se mantendrá a lo largo del siglo XVII ${ }^{15}$. La concordancia implica que el verbo ter mantiene su contenido semántico de posesión en estas construcciones.

Otro rasgo igualmente arcaizante de la formación de los tiempos compuestos que aún encontramos en estos autores es el uso del verbo ser como auxiliar: era usual aún en los autores estudiados de la primera mitad del siglo XVI y aún lo encontramos en Melo, aunque en éste se constata una progresiva substitución de este verbo por ter o haver ${ }^{16}$. Por lo que se refiere a las tres obras que son objeto de nuestro análisis, destaca una vez más el caso de Mística Teologia, pues, como se aprecia en la Tabla 4, es la única en que el uso de ser es minoritario con verbo [-transitivo]. Estos son algunos ejemplos de ser $+P P$ en tiempos compuestos:

Que doutra maneyra por demais fora elle [Christo] morto [= 'él hubiera muerto'], segundo diz S. Paulo na carta que escreueo aos de Galaçia (Mística Teologia)

Sam Paulo diz: fee sem obras he morta (Ortografia Portuguesa)

15 Mattos e Silva solo señalaba la pervivencia de concordancia a mediados del siglo XVI o, quizás, final de ese siglo («Vitórias...», pág. 130), pero la presencia de concordancia en Duarte Nunes de Leão y Rodrigues Lobo, como acabamos de ver, y aún más tarde en Melo (v. Carrasco González, J.M.: «Influencia...), retrasan considerablemente su final.

16 V. Carrasco González J.M., ibid. 
Vsaõse em fim as cousas mal, E ás vezes saõ nascidas de bom costume (Corte na Aldeia e Noites de Inverno)

Ejemplos de ter $+P P$ y haver $+P P$ con verbo [-transitivo]:

e tornou a dormir depois de auer comido (Mística Teologia) se hü he inclinado a trafegos, e negoçeos mundanos, ou se tem este viçio por longo exerçiçio, e cõuersação daquelles cõ quem ha tratado, corre risco em se meter frade (Mística Teologia)

Temos tratado dos contos graciosos, $\mathcal{E}$ ditos agudos (Corte na Aldeia e Noites de Inverno)

fingio hum dia saindo cõ alegre semblante auer-lhe fallado (Corte na Aldeia e Noites de Inverno)

\begin{tabular}{|c|c|c|c|}
\hline & Mística Teologia & Ortografia Portuguesa & Corte na Aldeia \\
\hline $\begin{array}{r}S E R \\
\text { (frecuencia) }\end{array}$ & $\begin{array}{c}1 \\
(16.7)\end{array}$ & $\begin{array}{c}1 \\
(100)\end{array}$ & $\begin{array}{c}5 \\
(50)\end{array}$ \\
\hline $\begin{array}{r}T E R \\
\text { (frecuencia) }\end{array}$ & $\begin{array}{c}0 \\
(0)\end{array}$ & $\begin{array}{c}0 \\
(0)\end{array}$ & $\begin{array}{c}3 \\
(30)\end{array}$ \\
\hline $\begin{array}{r}H A V E R \\
\text { (frecuencia) }\end{array}$ & $\begin{array}{c}5 \\
(83.3)\end{array}$ & $\begin{array}{c}0 \\
(0)\end{array}$ & $\begin{array}{c}2 \\
(20)\end{array}$ \\
\hline Total: & 6 & 1 & 10 \\
\hline
\end{tabular}

Tabla 4. Tiempos compuestos con verbo [-transitivo]

La explicación del uso mayoritario de haver como auxiliar con verbo [-transitivo] por parte de Sebastião Toscano también puede tener su origen en haber tomado al español como modelo, pues en esta lengua ya el verbo 'haber' había asumido la función de auxiliar en estos casos, desplazando a 'ser', sobre todo desde inicios del siglo XVI, de tal modo que desde finales de ese siglo 
el uso de 'ser' es raro, esporádico o afectado, de acuerdo con la descripción que ha llevado a cabo Javier Elvira ${ }^{17}$. Por su parte, Duarte Nunes de Leão no emplea nunca haver como auxiliar de tiempos compuestos (de ahí que posea también aquí 0 ocurrencias), mientras que Rodrigues Lobo lo usa de forma minoritaria (por lo que es normal que también en este uso tenga un número de ocurrencias inferior a los verbos ser y ter).

En definitiva, a pesar del escaso número de ocurrencias con que contamos para el análisis (no olvidemos que en portugués se usan poco los tiempos compuestos), es posible diferenciar perfectamente el caso de Sebastião Toscano, quien ofrece una frecuencia de uso de haver con verbo [-transitivo] (83.3 frente a 0 y 20 de los otros autores) más propio de la lengua castellana de la época que del portugués. Los otros autores (especialmente Rodrigues Lobo, donde es más fácil de percibir el uso) presentan una frecuencia de los distintos auxiliares más acorde con autores portugueses anteriores y posteriores ya estudiados, como Bernardim Ribeiro, João de Barros o incluso Francisco Manuel de Melo.

Para el portugués falta un estudio más detenido sobre los verbos que forman los tiempos compuestos con el auxiliar ser. Tradicionalmente se vienen señalando los verbos de movimiento, así como nascer, morrer y sinónimos (falecer, passar, etc. ${ }^{18}$. Es-

17 Elvira, Javier: «Intransitividad escindida en español: el uso auxiliar de 'ser' en español medieval», Estudios de Lingüística, no 15, 2001, págs. 201-246.

18 Rosa Virgínia Mattos e Silva señala que durante toda la Edad Media y el siglo XVI, por lo menos, se encuentran "sequências constituídas de ser + PP" en el caso de "um subconjunto de verbos classificados como intransitivos", tales como "nascer, morrer, falecer, passar (= 'morrer'), chegar, ir, correr (= 'passar o tempo')" (O português arcaico. Fonologia. morfologia e sintaxe, São Paulo, Editora Contexto, 2006, pág.139). Añade además que con el verbo ser se expresa en estos casos un " 'ato consumado', ou seja, do aspecto concluído ou perfectivo", recogiendo así la descripción que había hecho Augusto Epifânio da Silva Dias: "De alguns verbos (intransitivos ou tomados em sentido intransitivo) pode empregar-se o partic. passivo combinado com o verbo ser, para exprimir um acto consumado (v.g.: somos chegados, correspondente a chegámos)" (Syntaxe Historia Portuguesa, Lisboa, Livraria Clássica Editora, 1918, $\S 326$, p. 259). Este "acto consumado" es heredero de los tiempos compuestos de los 
tos verbos, propiamente intransitivos, son sin duda los que más fácilmente encontramos con tiempos compuestos formados con ser, pero no son los únicos. En Francisco Manuel de Melo, por ejemplo, encontramos amanhecer $\mathrm{y}$, en efecto, también entre los autores aquí estudiados vamos a encontrar otro tipo de verbos, como se puede comprobar en la Tabla $5^{19}$.

\begin{tabular}{|r|c|c|c|c|}
\cline { 2 - 5 } & morrer & nascer & passar (movimiento) & desposar com \\
\cline { 2 - 5 } Mística Teologia & 1 & 0 & 0 & 0 \\
\cline { 2 - 5 } Ortogragia Portuguesa & 1 & 0 & 0 & 0 \\
\cline { 2 - 5 } Corte na Aldeia & 0 & 1 & 3 & 1 \\
\cline { 2 - 5 } & & &
\end{tabular}

Tabla 5. Verbos conjugados con el auxiliar ser

\begin{tabular}{|c|c|c|c|c|c|c|c|}
\hline & andar & chegar & comer & falar & testar & tratar com & tratar de \\
\hline Mística Teologia & $\begin{array}{c}1 \\
\text { (haver) }\end{array}$ & 0 & $\begin{array}{c}3 \\
\text { (haver) }\end{array}$ & 0 & 0 & 1 (haver) & 0 \\
\hline Ortografia Portuguesa & 0 & 0 & 0 & 0 & 0 & 0 & 0 \\
\hline Corte na Aldeia & 0 & 1 (ter) & 0 & $\begin{array}{c}1 \\
\text { (haver) }\end{array}$ & $\begin{array}{c}1 \\
\text { (haver) }\end{array}$ & 0 & 2 (ter) \\
\hline
\end{tabular}

Tabla 6. Verbos de rasgo [-transitivo] conjugados con ter y haver

verbos deponentes latinos, que se construían con esse, $\mathrm{y}$, al igual que éstos, tienen significado activo pero una forma de pasiva analítica. No todas las construcciones de este tipo serán sustituidas por haver $+P P$ o ter $+P P$ en portugués moderno, sino también por estar $+P P$, "expressando o resultado e não só a ação concluída" (Mattos e Silva, R.V., idem, pág. 140). Todo ello revela que los tiempos compuestos de ser + PP estaban escasamente gramaticalizados.

19 Para el caso del español medieval, que se comporta de forma similar al portugués de la época, Javier Elvira establece los siguientes tipos de verbos que forman los tiempos compuestos con ser: (A) Verbos esencialmente intransitivos, compuestos por verbos de ocurrencia y acontecimiento, verbos de cambio de estado y aparición en escena (entre los que se encuentran fallecer, nacer, morir...), verbos de reposo y verbos de movimiento (como ir, exir, caer...); (B) Verbos transitivo-intransitivos, es decir, verbos intransitivos que también pueden ser usados de forma transitiva, cambiando o no de significado (v. Elvira, J.: «Intransitividad...»). 
De los tipos de verbos que tradicionalmente se señalan en portugués como los que propiamente construyen los tiempos compuestos con ser, observamos que en el caso de nascer y morrer todos los testimonios usan exclusivamente este auxiliar. Sin embargo, con los verbos de movimiento hay casos con distinto auxiliar (compárense las Tablas 5 y 6): Rodrigues Lobo utiliza ser con passar, pero utiliza ter con chegar. A su vez, Sebastião Toscano construye los tiempos compuestos de andar con el verbo haver. Finalmente, encontramos un caso de verbo de rasgo [-transitivo] que no podemos considerar propiamente intransitivo, sino verbo cuyo complemento rige preposición: desposar com en Rodrigues Lobo (que [eu] sendo desposado com ella secretamente). Según el Dicionário Terminológico da Língua Portuguesa aprobado por el Ministério da Educação de Portugal, actualmente en vigor, estos verbos serían transitivos indiretos com complemento oblíquo ${ }^{20}$. Adviértase, por otro lado, que desposar pertenece a la misma categoría de verbos de cambio de estado que morrer o nascer.

En cuanto a los verbos de rasgo [-transitivo] conjugados con ter o haver, aparte de algunos verbos de movimiento, aparecen dos casos de verbos transitivos indiretos com complemento oblíquo: tratar com (en Sebastião Toscano, conjugado con haver) y tratar de (en Rodrigues Lobo, conjugado con ter). También hay un caso de verbo transitivo-intransitivo: comer (conjugado con haver en la obra de Sebastião Toscano), al que podríamos añadir el caso de falar (conjugado con haver por Rodrigues Lobo), pues en la época podía eventualmente ser usado como transitivo direto. Y, finalmente, testar (también en la obra de Rodrigues Lobo, conjugado con haver), verbo intransitivo de diferente tipo de los que tradicionalmente se consideran propios para la construcción de los tiempos compuestos con ser.

Es posible establecer, pues, una descripción del uso de ser para los tiempos compuestos en este período algo diferente al uso

20 El Dicionário Terminológico se encuentra accesible en http://dt.dgidc.min-edu. pt/ (consultado el 21/01/2014). 
medieval y al uso que habitualmente aparece en las monografías especializadas. Por un lado, los verbos susceptibles de construir los tiempos compuestos con ser no se limitan solo a nascer, morrer (con sus sinónimos) y los de movimiento, sino también a otros verbos intransitivos y a verbos transitivos indiretos com complemento oblíquo. Seguramente en un corpus más extenso encontraríamos muchos más casos de verbos de rasgo [-transitivo] con ser. Por otro lado, se observa una disminución indudable del uso de ser en estas construcciones, pues ya aparece sustituido en ocasiones por ter o haver: aún no parece afectar a los verbos de cambio de estado (nascer, morrer), pero sí a los verbos de movimiento y a otros tipos de verbos con rasgo [-transitivo].

Por lo que se refiere a la anteposición del participio al auxiliar, rarísima en D. Francisco Manuel de Melo, es inexistente en las obras objeto de análisis en este trabajo. En este sentido, es posible afirmar que hay un evidente progreso en la gramaticalización de los tiempos compuestos con todos los auxiliares posibles en la época. Sin embargo, por lo que se refiere a la intercalación de elementos entre el auxiliar y el participio, hay bastantes ocurrencias en las obras de Sebastião Toscano y Rodrigues Lobo (no así en la de Duarte Nunes de Leão), como se puede observar en los siguientes ejemplos:

Auia este mançebo perguntado ao Senhor, q faria (Mistica Teologia)

Que doutra maneyra por demais fora elle morto, segundo diz S. Paulo (Mística Teologia)

q Deos agora tẽ em sua façe escõdidos ao mundo (Mística Teologia) Inverno)

por ser ja passada tanta parte da noite (Corte na Aldeia e Noites de

Por ouro tem a ira feitos abominaueis estragos (Corte na Aldeia e Noites de Inverno)

Que Duarte Nunes de Leão no haya realizado interpolaciones en estas construcciones puede deberse al tipo de obra que 
escribe: se trata de una obra de carácter técnico que quizás se prestaba menos al uso de determinados recursos estilísticos. Si esto es así (lo que podría corroborarse con el análisis de otras obras del autor, por ejemplo), cabría pensar que la interpolación era ya característica de determinados registros más cultistas y literaturizantes y, en consecuencia, impropia de la lengua hablada. También, por ese mismo motivo, no debe extrañarnos su abundancia aún en la prosa barroca de Melo.

\begin{tabular}{rr|c|c|c|} 
& & \multicolumn{1}{c}{ HAVER } & \multicolumn{1}{c}{ TER } & SER \\
\cline { 3 - 5 } Mística Teologia & total & 27 & 8 & 1 \\
& interpolación & 4 & 2 & 1 \\
(frecuencia) & $(14.81)$ & $(25)$ & $(100)$ \\
\hline \multirow{3}{*}{ Corte na Aldeia } & total & 5 & 88 & 5 \\
& interpolación & 0 & 12 & 1 \\
& (frecuencia) & $(0)$ & $(13.64)$ & $(20)$ \\
\cline { 3 - 5 } & & &
\end{tabular}

Tabla 7. Interpolación con los distintos verbos auxiliares ${ }^{21}$

Sea como fuere, lo cierto es que las interpolaciones en ambas obras son poco forzadas, pues normalmente se realizan con un único elemento entre el auxiliar y el participio: el sujeto, el complemento directo, un adverbio, etc. Sin embargo, Rodrigues Lobo muestra en muchos casos una característica que refuerza el arcaísmo de este recurso y la escasa gramaticalización de los tiempos compuestos: algunos de los elementos interpolados son modificadores directos del participio, como si este hiciese función nominal (adjetivo) y no verbal. Se trata de ejemplos como estos: se ha de ter tão leuantado, tendo-me tão mal acostumada, tẽ tam obrigados os desejos, etc. Adviértase, por otro

21 Se han excluido ahora los casos en que no había auténtico tiempo compuesto, lo que afecta en este caso a ter $+P P$ en Corte na Aldeia e Noites de Inverno, por eso no coincide con el número de ocurrencias de la Tabla 2. 
lado, que la frecuencia muestra un uso bastante minoritario de la interpolación en relación con el número total de ocurrencias de estas estructuras. Si obviamos las construcciones con menos ocurrencias (pues sus frecuencias no resultan significativas), los resultados son similares en ambas obras (v. Tabla 7): 14.81 con haver en Mística Teologia y 13.64 con ter en Corte na Aldeia e Noites de Inverno.

No aparece en ninguna de las obras un tiempo equivalente al pretérito anterior del español. En la obra de Melo solo he localizado tres ocurrencias, todas de $s e r+P P$. Ya en el portugués medieval no parece que fuese muy utilizado, pero no es difícil de localizar al menos en el período más arcaico. Joseph Huber ofrece una buena muestra de ejemplos sacados de la escuela lírica galaico-portuguesa (siglo XIII y primera mitad del XIV): “O definido anterior (= passé antérieur francês) é composta [sic] pelo definido de aver ou seer + particípio passado: por exemplo, ouve jurado (CD. 1655); eu fui nada (CD. 2009) [...]"22 La ausencia de este tiempo en las obras analizadas nos hace pensar en su desaparición en el período al que corresponden (segunda mitad del siglo XVI y primeras décadas del XVII), solo recuperado en autores como Melo por una posible influencia de la literatura en lengua española.

\section{Conclusiones}

Se confirma la hipótesis de que el uso del verbo haver como auxiliar en la formación de los tiempos compuestos, que había sido abandonado hacia 1540 a favor de ter, se recupera posteriormente $y$, aparentemente, solo en la lengua escrita culta más literaturizante. Como se trata de una cuestión de estilo, su uso (al menos en estos momentos iniciales de la recuperación) presenta una enorme disparidad de frecuencia entre unos autores y otros. Así, mientras que resulta mayoritario en Sebastião Toscano

22 Huber, Joseph: Gramática do Português Antigo, Tradução de Maria Manuela Gouveia Delille, Lisboa, Fundação Calouste Gulbenkian, 1986, §416, pág. 253. 
(77.1), es inexistente en Duarte Nunes de Leão; finalmente, ya en pleno siglo XVII, Francisco Rodrigues Lobo solo muestra algunas ocurrencias aisladas (5.3), lo que demuestra que la recuperación de haver $+P P$ fue lenta, aunque sin duda había penetrado ya en la lengua culta de la época incluso en autores que, como Rodrigues Lobo, no muestran ninguna predilección por esta estructura.

También se reafirma la idea de que en la recuperación de ha$v e r+P P$ intervino indudablemente la influencia del modelo castellano, puesto que, comparando la concordancia del participio con el complemento que aún se mantiene en ter $+P P$, se observa que haver $+P P$ se comporta más como lo hacía en español ya en ese momento que como era habitual en los tiempos compuestos del portugués.

La construcción de tiempos compuestos con el verbo ser todavía se mantiene en estos autores con verbos de rasgo [-transitivo], pero alternando ya con ter o haver. La situación es similar a la que encontraremos más tarde en la obra de Melo.

Quizás lo que más claramente muestre el avance de la gramaticalización a mediados del siglo XVII con respecto a los autores aquí estudiados sea la concordancia del participio con el complemento, puesto que se constata una frecuencia mayor en estos que en D. Francisco Manuel de Melo. En el Gráfico 1 se puede ver la frecuencia de concordancia en autores de los siglos XVI y XVII: el fenómeno disminuye rápidamente su frencuencia en la primera mitad del siglo XVI (desde 92.3 en Bernardim ${ }^{23}$ hasta 41.7 en las cartas de D. João $\left.\mathrm{III}^{24}\right)$, pero se estabiliza entonces hasta principios del siglo XVII (Rodrigues

23 Tomo los datos de Carrasco González, J.M.: «Uso de haver...».

24 V. Mattos e Silva, R.V.: «A variação...». 
Lobo presenta una frecuencia de 56.8$)^{25}$ para volver a reducir su frecuencia en los autores de mediados del XVII (en Melo se alzanza solo el 16.6$)^{26}$.

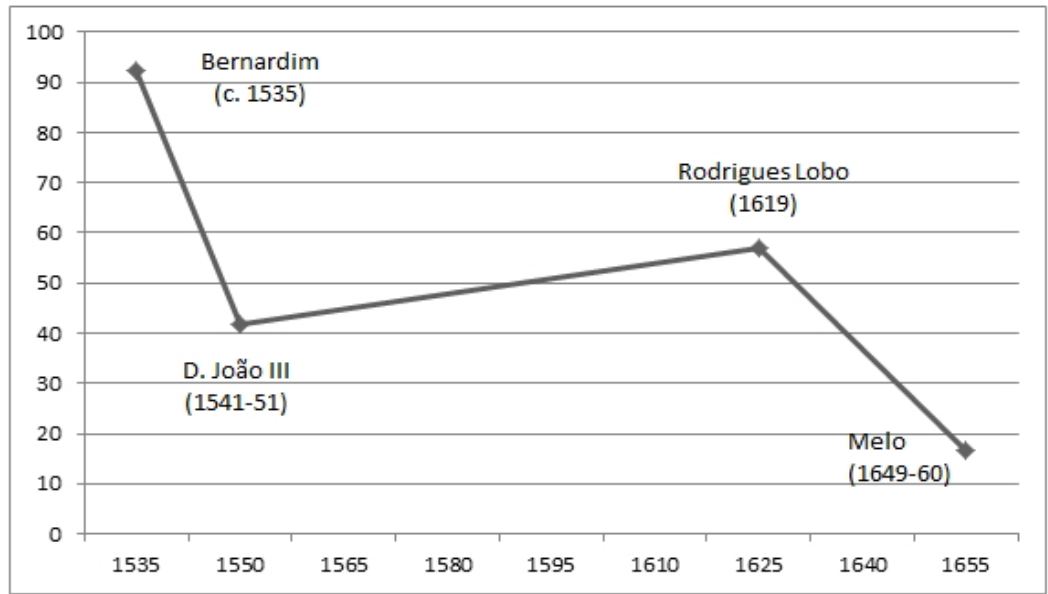

Gráfico 1. Frecuencia de la concordancia entre participio y complemento

Otros fenómenos estudiados que afectan al grado de gramaticalización de los tiempos compuestos no difieren mucho de lo que encontramos en D. Francisco Manuel de Melo a mediados del siglo XVII: hay una abundante interpolación de elementos entre el auxiliar y el participio, pero no hay anteposición del participio al auxiliar (con alguna ocurrencia aislada en Melo), ni uso del pretérito anterior (aún presente en Melo, quizás también por influencia del español).

25 No tomo en consideración los casos de Mística Teologia y Ortografia Portugue$s a$, porque son tan escasas las ocurrencias en estas obras que sus frecuencias de uso están necesariamente distorsionadas.

26 V. Carrasco González, J.M., «Influencia...». 
Finalmente, es importante advertir sobre una conclusión de este estudio que afecta a la metodología en el análisis de corpora lingüísticos. Al establecer un corpus bien definido por autores y tipos de obras (u otros textos escogidos), dentro de un período temporal relativamente corto y bien datado, como es el caso del presente estudio, es posible determinar numerosos detalles en la evolución de la lengua y en el uso de sus estructuras que es imposible de detectar en grandes corpora correspondientes a períodos extensos. Los resultados obtenidos por Paulo Osório en cuanto al uso de haver $+P P$ y ter $+P P$ en la Edad Media y el siglo $\mathrm{XVI}$, aunque son bien significativos en cuanto a la paulatina sustitución de un verbo por el otro, no nos revelan hechos fundamentales en la historia de esta estructura verbal como son: que hacia 1540 se había dejado de usar haver $+P P$; que se recupera el uso del auxiliar haver de forma irregular, en la lengua escrita más literaturizante, en la segunda mitad del siglo XVI y se extiende en el XVII con un uso culto similar al de nuestros días; que seguramente existió una influencia de la lengua española en este proceso de recuperación; que el tipo de obra y los gustos de cada autor pueden hacer variar la frecuencia de uso considerablemente; etc. Ambas metodologías son, pues, complementarias e igualmente necesarias.

Juan M. Carrasco González UNIVERSIDAD DE EXTREMADURA 